\title{
The alcohol deficit: Canadian government revenue and societal costs from alcohol
}

\author{
Adam Sherk, PhD
}

Tweet this article

\begin{abstract}
This summary article compares government revenue from the sale and distribution of alcohol to the societal costs caused by alcohol use for the year 2014. Statistics Canada data reported government revenue of $\$ 10.9$ billion; however, this was offset by net societal costs of $\$ 14.6$ billion, as reported by Canada's national substance use surveillance system, the Canadian Substance Use Costs and Harms project. The societal costs include health care, economic loss of production, criminal justice and other direct costs. Though revenue from alcohol sales has been described as a benefit to public coffers, accounting that includes costs incurred shows that all provinces and territories in Canada are running an alcohol deficit, totalling $\$ 3.7$ billion nationally.
\end{abstract}

Keywords: alcohol use, costs, societal costs, Canadian Substance Use Costs and Harms, alcohol deficit

\section{Introduction}

Canadian government revenue generated from the sale and distribution of alcohol has been described as a boon to public coffers, as this revenue may then be redirected towards health care and education. Indeed, a look at the public accounts makes it clear that the sale of alcohol is lucrative, providing significant revenues to federal and provincial governments. ${ }^{1}$ However, as more than $75 \%$ of Canadian adults drank alcohol in the past year, ${ }^{2}$ these revenues are balanced against substantial and growing $\operatorname{costs}^{3}$ due to population-wide exposure to alcohol. These societal costs include health care, lost productivity, criminal justice and other direct costs.

Government revenues generated from the sale of alcoholic beverages, in the form of federal excise tax, net income from provincial liquor authorities and sales tax (such as harmonized sakes tax [HST], provincial sales tax [PST] and goods and services tax [GST]) have been recorded by Statistics Canada for some time. ${ }^{1}$ However, Canada was without a national substance use surveillance system for more than a decade until the completion of the Canadian Substance Use Costs and Harms (CSUCH) project in 2018. ${ }^{3} \mathrm{CSUCH}$ details a comprehensive accounting of the societal costs associated with eight different psychoactive substances, including alcohol. At \$14.6 billion, alcohol was the most costly substance in Canada in 2014, with costs higher than tobacco ( $\$ 12.0$ billion) and far higher than opioids ( $\$ 3.5$ billion) and cannabis ( $\$ 2.8$ billion). ${ }^{3}$

This summary article answers the following question: When considering net revenue and net societal costs, do Canadian governments run an alcohol surplus or an alcohol deficit?

\section{Methods}

The conceptual framework used by the data sources described next is a counterfactual scenario wherein population exposure to alcohol use is, and has always been, zero. Neither source, nor this summary article, takes the stance that alcohol use should be zero: this is simply a means of accounting government revenue and

\section{Highlights}

- Canada runs an alcohol deficit of about $\$ 3.7$ billion per year, when accounting considers both government revenue and societal costs from established sources.

- Government revenue totalled $\$ 10.9$ billion in 2014 , but this was more than offset by societal costs of $\$ 14.6$ billion, as reported by the Canadian Substance Use Costs and Harms project.

- Societal costs include health care, lost productivity, criminal justice and other direct costs.

- Among provinces and on a per capita basis, Alberta had the lowest government revenue and the highest alcohol deficit.

societal costs caused, or attributed, to alcohol.

Provincial/territorial level data on net income of liquor authorities and government revenue from the sale of alcohol were from Statistics Canada's CANSIM database for fiscal year 2014/15. ${ }^{1}$ Downloaded data had a greater level of granularity than that presented in this article; I used the existing table heading "net income of liquor authorities" and row stub heading "federal excise tax and customs duties." I grouped all other taxes and revenue categories into "sales tax and other revenue."

$\mathrm{CSUCH}$ presents economic costs incurred by society in 19 categories across four domains (health care, economic loss of production, criminal justice and other

\section{Author reference:}

Canadian Institute for Substance Use Research, University of Victoria, Victoria, British Columbia, Canada

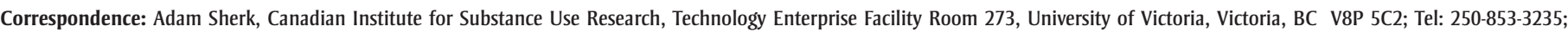
Email: asherk@uvic.ca 
direct costs). Provincial/territorial data for 2014 in these four cost categories were from the CSUCH online visualization tool (https://csuch.ca/explore-the-data/) on 4 December 2019. Detailed methodology regarding each of the domains, as well as for the CSUCH project, is described elsewhere. ${ }^{3,4}$ The CSUCH project underestimated health care costs in the province of Quebec due to the lack of data availability in certain categories in that province.

For each province and territory as well as Canada as a whole, total net deficits/surpluses were calculated as the difference between net revenue and net costs. I use the terms "net revenue" and "net costs" as costs (when discussing net revenue) and savings (when discussing net costs) have already been accounted for. For example, the net revenue category "net income from liquor authorities" has already had product costs, administrative expenses and employee salaries deducted from gross sales. In terms of health care costs, low doses of alcohol may have a slightly protective effect on some health conditions, such as diabetes ${ }^{5}$, and ischemic heart disease in women ${ }^{6}$; the cost savings of this on the health care system have already been included in the "net cost” figures. Per capita figures were calculated using provincial populations on 1 July $2014 .^{\text {? }}$

\section{Results}

Significant government revenue-a total of nearly $\$ 10.9$ billion-was generated from the sale of alcohol in 2014 (see Table 1). However, this is more than balanced by the outlay of $\$ 14.6$ billion caused by alcohol consumption, resulting in an annual national government deficit of about $\$ 3.7$ billion in 2014 .

Among revenue categories, net income from liquor authorities was the largest national contributor at $\$ 5.7$ billion ( $52 \%$ ), followed by sales tax and other revenue at $\$ 3.7$ billion (34\%) and federal excise tax at $\$ 1.5$ billion (14\%). Net income from liquor authorities was the largest component of government revenue in all jurisdictions except Prince Edward Island and Quebec, where sales tax and other revenue was the largest category.

Examination of costs incurred show that economic loss of production contributed the highest proportion of alcohol-caused costs at $\$ 5.9$ billion (40\%), followed by costs incurred by the health care system at $\$ 4.2$ billion (29\%), criminal justice outlays at $\$ 3.2$ billion (22\%) and other direct costs at $\$ 1.34$ billion (9\%). Note that the CSUCH project underestimated health care costs in Quebec due to lack of data availability in several health care categories. ${ }^{3}$

Examination of per capita government revenue, costs and deficits shows significant regional differences (see Table 2). Of all the provinces, Alberta has the lowest per capita revenue at $\$ 272$ per person (pp) and the highest per capita costs at $\$ 587$ pp, leading to a per person deficit ( $\$ 315$ pp) more than double that of the next highest province and almost six times the national average. Quebec has the lowest per capita deficit; however, as noted health care costs were not fully accounted for. Newfoundland and Labrador (\$52 pp), Nova Scotia $(\$ 58 \mathrm{pp})$, Prince Edward Island (\$70 pp), New Brunswick (\$104 pp) and Ontario (\$105 pp) had per capita deficits below the national average (\$106 pp). Deficits in the territories were substantially higher than this national average.

TABLE 1

Government alcohol net revenue, net costs and net deficit, by jurisdiction and Canada, 2014

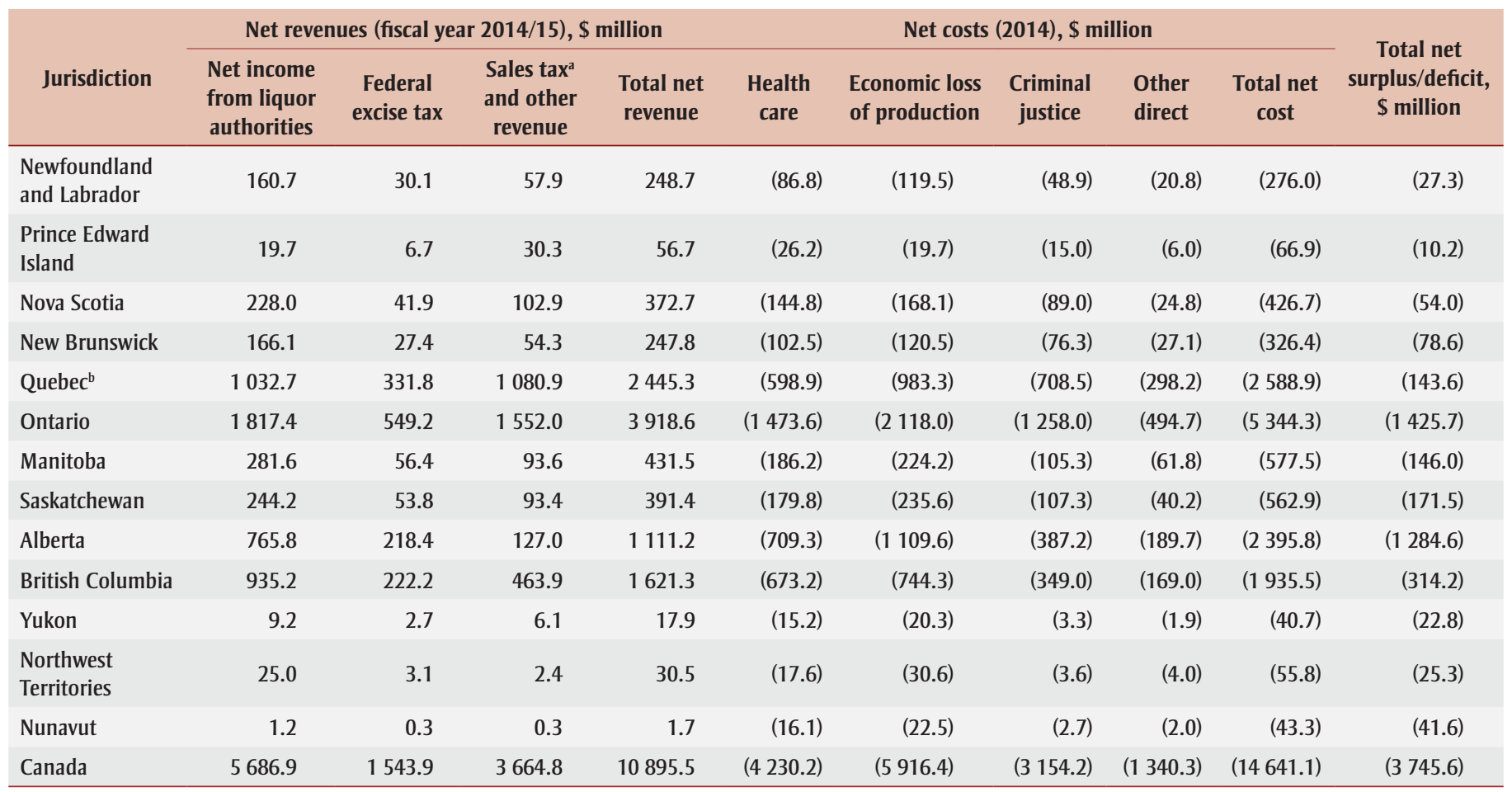

Note: Numbers in parentheses are negative.

${ }^{\text {a }}$ Provincial sales tax (PST), harmonized sales tax (HST) or goods and services tax (GST).

${ }^{\mathrm{b}}$ According to Canadian Substance Use Costs and Harms: 2007-2014, ${ }^{3}$ health care costs in Quebec are not fully enumerated due to data access issues; these costs are therefore underestimates. 
TABLE 2

Per capita net revenue, net cost and net deficit, by jurisdiction and Canada, 2014

\begin{tabular}{lcrr} 
& \multicolumn{3}{c}{ Per person, $\$$} \\
\cline { 2 - 4 } \multicolumn{1}{c}{ Jurisdiction } & $\begin{array}{c}\text { Net government } \\
\text { revenue }\end{array}$ & Net cost & Net surplus or deficit \\
\hline Newfoundland and Labrador & 471.0 & $(522.6)$ & $(51.6)$ \\
Prince Edward Island & 393.3 & $(463.7)$ & $(70.4)$ \\
Nova Scotia & 397.2 & $(454.6)$ & $(57.5)$ \\
New Brunswick & 326.5 & $(430.1)$ & $(103.6)$ \\
Quebec ${ }^{\text {a }}$ & 300.0 & $(317.6)$ & $(17.6)$ \\
Ontario & 287.8 & $(392.5)$ & $(104.7)$ \\
Manitoba & 337.4 & $(451.5)$ & $(114.1)$ \\
Saskatchewan & 351.6 & $(505.8)$ & $(154.1)$ \\
Alberta & 272.1 & $(586.7)$ & $(314.6)$ \\
British Columbia & 344.4 & $(411.2)$ & $(66.7)$ \\
Yukon & 483.0 & $(1095.9)$ & $(613.0)$ \\
Northwest Territories & 695.3 & $(1271.5)$ & $(576.2)$ \\
Nunavut & 48.5 & $(1203.7)$ & $(1155.2)$ \\
Canada & 307.5 & $(413.2)$ & $(105.7)$ \\
\hline
\end{tabular}

Note: Numbers in parentheses are negative.

according to Canadian Substance Use Costs and Harms: 2007-2014, ${ }^{3}$ health care costs in Quebec are not fully enumerated due to data access issues; these costs are therefore underestimates.

\section{Discussion}

An accounting of government revenue, as well as societal costs, associated with alcohol sales and alcohol use in Canada shows that alcohol surpluses are a misconception. In all 13 jurisdictions, societal costs are higher than government revenue, resulting in an "alcohol deficit" of $\$ 3.7$ billion in Canada during 2014.

This summary article has limitations, as the data sources used to estimate government revenue and societal cost include incomplete accounting and are likely to be underestimated. Alcohol-producing businesses and individuals working in alcohol commerce pay corporate and personal income tax to federal or provincial governments. This could be considered indirect government revenue resulting from alcohol use in Canada. On the other hand, as noted above, the conceptual framework of this study is a counterfactual scenario with zero population exposure to alcohol. This study does not recommend this scenario, only its use for scenario-based accounting. In this counterfactual scenario, entrepreneurs and corporations would enter other sectors of the economy, as opposed to the alcohol industry. The overall economic effect of this diversion of energy and capital away from the production and sale of alcohol to other sectors is difficult to determine.
The societal costs of alcohol use captured in CSUCH may be significantly underestimated, as some cost categories could not be enumerated due to methodological or data restraints. For example, CSUCH does not include the cost of human pain and suffering experienced by individuals and those in their social networks linked to alcohol-caused health conditions. Nor does it include economic loss of production due to incarceration, the life course cost of fetal alcohol spectrum disorder and private treatment costs. ${ }^{3}$

\section{Conclusion}

Societal costs, including health care, economic loss of production, criminal justice and other direct costs, were substantially higher than government alcohol-related revenue in all provinces and territories in 2014. Nationally, government revenue of $\$ 10.9$ billion is below the societal cost of $\$ 14.6$ billion estimated by the CSUCH study, resulting in an annual, ongoing alcohol deficit of $\$ 3.7$ billion. It is clear we are robbing Peter to pay Paul.

\section{Acknowledgements}

This work was made possible through a Postdoctoral Fellowship from the Canadian Institutes of Health Research.

\section{Conflicts of interest}

AS was a Guest Editor for this issue of the HPCDP Journal, but removed himself from the editorial decision-making associated with this manuscript.

\section{Author's contributions and statement}

AS was responsible for all portions of the article.

The content and views expressed in this article are those of the authors and do not necessarily reflect those of the Government of Canada.

\section{References}

1. Statistics Canada. Net income of liquor authorities and government revenue from sale of alcoholic beverages $(\times 1,000)$. Frequency: annual. Table: 10-10-0012-01 (formerly CANSIM 183-0025). Geography: Canada, Province or territory [Internet]. Ottawa (ON): Statistics Canada; [cited 2019 Dec 4]. Available from: https://www150 .statcan.gc.ca/t1/tbl1/en/tv.action ?pid $=1010001201$

2. Sherk A, Gilmore W, Churchill S, Lensvelt E, Stockwell T, Chikritzhs T. implications of cardioprotective assumptions for national drinking guidelines and alcohol harm monitoring systems. Int J Environ Res Public Health. 2019;16(24). doi:10.3390/ijerph16244 956.

3. Canadian Substance Use Costs and Harms Scientific Working Group. Canadian substance use costs and harms (2007-2014). (Prepared by the Canadian Institute for Substance Use Research and the Canadian Centre on Substance Use and Addiction). Ottawa (ON): Canadian Centre on Substance Use and Addiction; 2018.

4. Sorge JT, Young M, Maloney-Hall B, et al. Estimation of the impacts of substance use on workplace productivity: a hybrid human capital and prevalence-based approach applied to Canada. Can J Public Health. 2020; 111(2):202-11. doi:10.17269/s41997 $-019-00271-8$. 
5. Knott C, Bell S, Britton A. Alcohol consumption and the risk of type 2 diabetes: a systematic review and dose-response meta-analysis of more than 1.9 million individuals from 38 observational studies. Diabetes Care. 2015;38(9):1804-12. doi:10.2337/dc15 -0710 .

6. Roerecke M, Rehm J. The cardioprotective association of average alcohol consumption and ischaemic heart disease: a systematic review and meta-analysis. Addiction. 2012;107(7): 1246-60. doi:10.1111/j.1360-0443.2012 .03780.x.

7. Statistics Canada. Population estimates on July 1st, by age and sex. Frequency: annual. Table: 17-100005-01 (formerly CANSIM 051-0001). Geography: Canada, province or territory [Internet]. Ottawa (ON): Statistics Canada; [cited 2019 Dec 4]. Available from: https://www150 .statcan.gc.ca/t1/tbl1/en/tv.action ?pid $=1710000501$ 